\title{
Strong Girls, Strong Women
}

\author{
Rochelle Starr \\ University of Alberta \\ rmstarr@ualberta.ca
}

Young Indigenous Women's Circle of Leadership (YIWCL) is a Cree Immersion Program for young women between the ages of 10-16 and is housed within the Faculty of Education, at the University of Alberta. YIWCL is an eight-day program that runs during the summer and then has additional call-backs throughout the year to continue working with the young women in a mentorship capacity. YIWCL is taught by fluent Cree first language speakers and traditional knowledge holders.

The intention of this program is to support the survival of Indigenous language, identity and traditional teachings. The purpose of this program is to provide young women with access to language, traditions, ceremonies, and land. The Cree teachings around language is that Cree is a spiritual language and therefore, the foundation of the program and for teaching Cree is a spiritual process. The young women are taken to various ceremonies on the land. Cree instructors teach Cree by way of traditional pedagogical approaches. Cree in Motion is the term that we use, which is about teaching Cree by doing - The Cree instructors and Elders speak to the girls in Cree during ceremonies, picking medicine, while sharing teachings that speak to their identity as young Indigenous women and the value of women in community. Cree in Motion is a form of experiential learning and is a process of learning Cree where the learners learn while doing and are grounded and connected to the language within a spiritual context. For example, our most recent call-back session included a naming ceremony for the young women and their families. Receiving a spiritual name in Cree is a critical event for Cree people as it connects individuals spiritually and informs their identity.

All the activities are grounded within Cree ways of knowing and being and are not only taught how, but also why the teachings, ceremonies and land are important, meaning that the epistemological and ontological aspects of Indigenous philosophy are brought to the forefront.

The young women are provided with the experience and the awareness of what it means to be able to live and be who they are as Indigenous people. Activities that are taught within the Cree epistemic foundations, which are led by Indigenous knowledge holders and language keepers include rattle making, sharing of the Cree creation story, moss bag teachings, teachings of the buffalo, singing, praying, smudging, sweat ceremony, water ceremony, Cree art, bead work, star blanket teachings, kinship teachings, leadership teachings, Cree fitness and much more. All the teachings also take into consideration the current realities which help the young women navigate the socio-economic distress that many endure such as the child welfare system, racism, impacts of IRS, and missing and murdered Indigenous women.

Cultural and Pedagogical Inquiry, Fall 2018, 10(2), pp. 47-48

ISSN 1916-3460 @ 2018 University of Alberta

http://ejournals.library.ualberta.ca/index.php/cpi/index 
Essentially, this program provides young women with access to knowledge of their ancestors. This knowledge gives them the connection, strength, and understanding of who they are as young Indigenous women. YIWCL's ultimate goal is that the young women will have the knowledge, the language, the spiritual connection, and the tools to create their lives, beautifully.

\section{Note:}

To view a video on the Young Indigenous Women's Circle of Leadership Program, the following link is available on YouTube:

https://www.youtube.com/watch?v=W7mukkac2q0\&feature=youtu.be 